Article

\title{
The Need for Geoethics Awareness from a Canadian Perspective
}

\author{
Anne Marie Ryan ${ }^{1, *}$ and Carl-Georg Bank ${ }^{2}$ \\ 1 Earth Sciences, Dalhousie University, 1459 Oxford Street, Halifax, NS B3H 4R2, Canada \\ 2 Earth Sciences, University of Toronto, 22 Russell Street, Toronto, ON M5S 3B1, Canada; \\ charly.bank@utoronto.ca \\ * Correspondence: amryan@dal.ca; Tel.: +1-902-494-3184
}

Received: 9 October 2017; Accepted: 14 November 2017; Published: 21 November 2017

\begin{abstract}
An online survey of Canadian Earth scientists on geoethics-defined as the interconnection between humanity and Earth sciences-asked participants to (1) rate the importance of issues around scientific integrity, social responsibility, aboriginal concerns, corporate ethics, and fieldwork; (2) identify ethical considerations they had observed; and (3) tell us how they were introduced to ethical viewpoints and whether their undergraduate programs had prepared them for ethical decision-making. Despite a small sample size (123 responded to our survey) we observe that most respondents deemed all criteria we listed as important or very important, with the strongest support for health/safety and honest reporting, and the least, but still significant support for criteria linked to aboriginal issues and fieldwork. Many respondents had observed ethical considerations, particularly lack of giving credit and biased representation of information. We find that informal activities like reading and discussions with peers are the most frequent avenues into geoethics, while undergraduate education is not a significant contributor to current geoethics understandings. Although the survey was restricted to Canada, we perceive our survey as providing a glimpse into the larger geoscience community and offer various recommendations on how the geoscience community and public must be made aware of geoethics, not just in Canada.
\end{abstract}

Keywords: geoethics; undergraduate education; geoscience community; Canadian

\section{Introduction}

Earth scientists can no longer ignore the impact of their science on the societal and political realm, and society can no longer ignore the role of the Earth sciences in today's world. Increasingly, Earth scientists face considerations of an ethical nature; yet our formal education typically does not address such issues in a systematic way. In recent years, professional geoscientist associations have formed across most jurisdictions in Canada. These have developed a Code of Ethics for professional practice, and require an ethics exam for full admittance into the respective association [1]. Efforts are also under way to consider an internationally accepted code of practice [2,3], including the Capetown Statement [4] which is widely endorsed. Some even suggest geoscientists swear an oath similar to the Hippocratic Oath for physicians [4,5], to express their moral obligations towards society and the planet; and have provided a proposal for such an oath [4,6]. Others challenge the global geoscience community to stress the importance of developing ethical bases for geoscientists-particularly in light of the growing impact of natural hazards on increased populations and urban centres, our natural resources, and issues such as climate change [7], and contend that geoscientists "should be at the service of the common good" [8].

Learned societies have started to include ethics sessions in their meetings (for example: European Geosciences Union, April 2013; Geological Association of Canada and Mineralogical Association of Canada, May 2013; International Association for Engineering Geology and the Environment, 
September 2014; European Geosciences Union, April 2015; Joint Assembly American Geophysical Union-Geological Association of Canada-Mineralogical Association of Canada-Canadian Geophysical Union, May 2015; International Geological Congress, August/September 2016), and some (notably American Geosciences Institute, American Geophysical Union, Geological Society of America) have even strengthened their ethics policies. However, at this time we lack a clear understanding of the range of ethical considerations an Earth scientist may face in her/his career, and whether the education of Earth scientists includes any training in ethical behavior. Further, we do not have a clear understanding of the state of ethics education in Earth sciences.

In this paper we summarize the results of a survey intended to address the following questions: (1) What is the current awareness and nature of ethical issues in the Canadian Earth science community and (2) What ethical principles do our students need to learn? These questions in turn, lead us to consider: (3) How do we best educate to high ethical standards in our Canadian Earth sciences programs? Our interest is in considering current levels of awareness and engagement in geoethics-related issues, and not in judging ethical behavior. We stress that we did not restrict our considerations to professional ethics but rather to geoethics more broadly defined. The two of us are particularly interested about the Canadian context, given that we teach at Canadian universities and because Canadian companies and their Earth scientists work throughout the world. Therefore we think our study provides a glimpse into considerations relevant for the wider geoscience community, including whether there is a need for greater attention to geoethical education in our undergraduate programs.

\section{What Is Geoethics?}

Geoethics, an evolving field, explores the overlap between geoscience and ethics, and addresses in particular the interconnection between humanity and geology, and our role as geoscientists within this interaction.

The Capetown Statement by the International Association for the Promotion of Geoethics (IAPG) defines geoethics as follows [4]: "Geoethics consists of research and reflection on the values which underpin appropriate behaviors and practices, wherever human activities interact with the earth system. Geoethics deals with the ethical, social and cultural implications of geosciences knowledge, education, research, practice and communication, and with the social role and responsibility of geoscientists in conducting their activities."

And the International Association for Geoethics (IAGETH) incorporates the following definition [9]: "Geoethics is an interdisciplinary field between Geosciences and Ethics which involves Earth and Planetary Sciences as well as applied ethics. It deals with the way of human thinking and action in relation to the significance of the Earth as a system and as a model. In addition, the necessity of considering appropriate protocols, scientific integrity issues and a code of good practice-regarding the study of the abiotic world-is covered by this discipline."

In Canada, regulatory bodies for geoscience professionals are governed by provincial and territorial jurisdiction. Geoscientists Canada was formed in 1996 to develop an alliance for the geoscience profession [1]. An important aspect of professionalism in geoscience in Canada and elsewhere is that of professional ethics. Most jurisdictions within Canada have a code of ethics that encompasses, among others, the "right" behaviour with respect to society as a whole, clients, and colleagues, as well as employers and employees, and requires the passing of an ethics exam.

As instructors of undergraduate students, we are struck by the apparent widespread absence or scarcity of any formal education in geoscience ethics in undergraduate programs, not just in Canada, but elsewhere as well. In the US, the recent development of a web resource to encourage and support the teaching of geoethics provides information on the current state of teaching geoethics, and some resources for incorporating the topic into the undergraduate curriculum [10], however, although this is an encouraging development, it does not imply that geoethics has been formally integrated into curricula. This seems potentially problematic in light of the increasing awareness and recognition 
of the role of geoscience in society globally. Are our students familiar with ethical decision-making in aspects of the geosciences? Is the requirement for an ethics exam sufficient to ensure that the geoscience workforce operates in ethically responsible ways? Is there something more we as educators could or should be doing to ensure our students have a solid grounding in the principles of ethical decision-making, and in the types of ethical aspects that can arise when working in the geosciences? While there are numerous courses on ethics, and on ethics in science more broadly, a scan through the literature on ethics education does not reveal anything specific around geoscience ethics education in particular and neither does it identify specific methodologies or concerns to address this within the field of geoscience at the undergraduate level. As far back as 1958, Dougherty spoke to the need for ethical behaviour around mineral exploration and extraction specifically [11]. In 1976, Bok asked the question: "Can Ethics Be Taught?" In which he concluded that, despite limitations, we should be providing students with the opportunity to problem-solve around ethical aspects within our courses [12].

These various considerations and suggestions prompted us to embark on a study to ascertain what the geoscience community might regard as ethical behaviour, and whether they saw such behaviour violated in the course of their work environment. Our premise was that, if behaviour was always ethical, then there is likely no real need to consider teaching undergraduates differently. If, however, there were discrepancies, then developing approaches to address ethical issues within undergraduate programs may not only be of benefit, but has to be considered an ethical responsibility that we need to address.

\section{The Study}

With ethics approval from the University of Toronto and Dalhousie University, we developed a questionnaire for distribution to the wider Canadian geoscience community, and to which respondents could reply with assurance of anonymity. In developing this questionnaire, we identified five categories around potential ethical issues that a geoscientist might encounter during their working life: (1) issues of scientific integrity; (2) issues of social responsibility; (3) issues around aboriginal concerns; (4) issues of corporate ethics; and (5) issues around fieldwork. We also invited input on other potential aspects that we may have missed. We generated a list of potential areas in which ethical considerations could arise involving one or more of these five categories, and asked respondents to identify all in the list that they had observed while working as a geoscientist (and not whether they had been involved personally). In addition, we asked respondents to indicate how they had been introduced to ethical viewpoints and decision-making related to Earth sciences in particular, and whether they felt their undergraduate program had prepared them for the ethical decision-making they needed as professional geoscientists.

In developing the survey, we considered not only what we thought might be universally accepted as ethical or unethical behaviour, but also what might be considered either specifically legal aspects or specifically good (or bad) practice, while not actually violating universal ethical criteria. In making this decision, we recognised that although there are universal ethics, there are also ethics that are specific to an individual's culture or background, and what may be ethical in one cultural context may not in another.

This survey was sent to a variety of geoscience groups and associations across Canada in the spring and summer of 2013, in an attempt to get a cross-section of geoscientists from those working in different areas of geoscience, as well as from individuals at various stages in their careers. Because the survey was anonymous, we do not know how widely the survey was distributed or how it was distributed. As we were more interested in getting a cross-section view from the profession, we were less concerned with total numbers of responses than with ensuring we had tapped the main sub-fields of the working geoscientist (government, mining and exploration, petroleum, environmental geoscience, teaching, and research). We received 123 responses from a Canadian cross-section of individuals working in a variety of geoscience concentrations, and at various stages in their careers. We acknowledge that these numbers are not high and although we do not have evidence to indicate 
bias, it is possible that those who respond more strongly to ethical considerations may have been more inclined to complete the survey. However, it should be noted that those responding do represent a cross-section of the geoscience community both geographically and by sector. We did also receive responses from international geoscientists, however, as our ethics approval did not extend to include these, they are not discussed here. We invited comments and input from respondents regarding any or all of the questions, and asked that they indicate whether their comments could be quoted.

\section{Results}

Our aim was not necessarily to target every geoscientist in Canada, but rather to get a cross-section of the community, both those currently working in it as well as retirees and students. Figure 1 shows the distribution of the background and work experience (or student background) for the respondents. Whereas the number of completed responses was 123 in total-very small compared to the estimated 20,000 Canadian professional geoscientist [1], and possibly biased towards those individuals who have encountered ethical issues-the data provide a balanced cross-section of government, mineral, environmental, and petroleum sectors, as well as academia (both faculty and students) and retired geoscientists. According to the affiliations participants provided as answer to one question we note that they hail from across the country, that is Atlantic Canada, Ontario, the Prairies, Western Canada and the Territories.

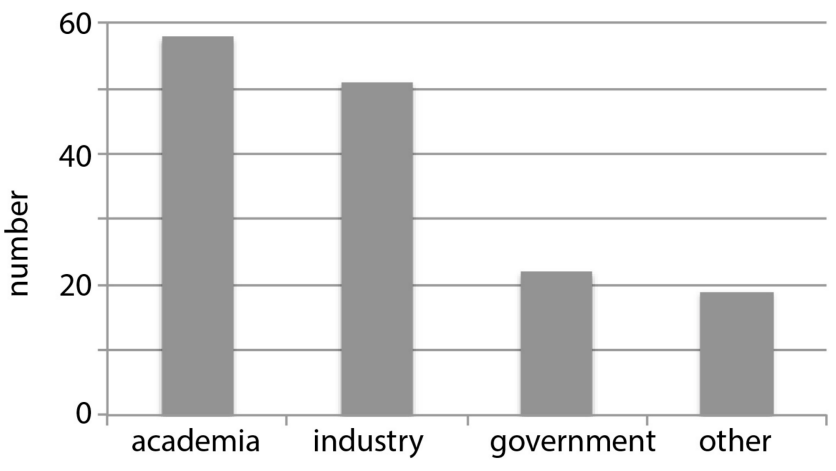

Figure 1. Distribution of survey participants.

Data from questions revolving around the five categories are presented in Figure 2a-e. In each case participants were asked to consider the relative importance of a set of criteria within each category, and rate as "extremely important", "important", or as a "minor ethical issue". Participants were also given the opportunity to include a short written comment suggesting an additional criteria or additional information they considered relevant in each case.

In terms of issues surrounding scientific integrity (Figure 2a) all of the listed criteria were considered important or extremely important by more than $96 \%$ of respondents, with honest reporting receiving the highest ranking in terms of extreme importance (93\%) and referencing receiving the lowest in terms of extreme importance (but still with 52\% considering this extremely important). One respondent suggested that we also include "cooperation and communication between geoscientists, especially relating to application of best-practice science" and "application of continuing education for practicing professionals". We agree that these are additional considerations, and speak to the need for greater intra-professional communication and the importance of ongoing professional development, both of which may well contribute to good ethical behaviour.

Figure $2 \mathrm{~b}$ summarizes the results under the social responsibility category, and shows that over $50 \%$ of respondents considered human rights, stewardship, sustainability, and communication of Earth sciences to the wider public to be of extreme importance. On the other end of the scale, just $19 \%$ indicate that geoheritage concerns were of extreme importance, although we note that at least one respondent indicated they did not know the meaning of geoheritage. (Also only $45 \%$ consider 
"respect" as extremely important.) Overall, over $73 \%$ of respondents indicated that all criteria under the umbrella of social responsibility were important or extremely important. Additional comments from respondents with respect to social (and environmental) responsibility conclude (1) there is a realization that "social and environmental responsibility should be a much higher priority than it currently is for Canadian Earth Scientists", and (2) there is a need for increased "communication and cooperation between engineers and geoscientists to mitigate and/or manage recognized geohazards". These suggest that greater awareness in general, and greater connection and communication between Earth scientists and other professionals (such as engineers in the quote given) are also important, and should contribute to the discussion around geoethics.

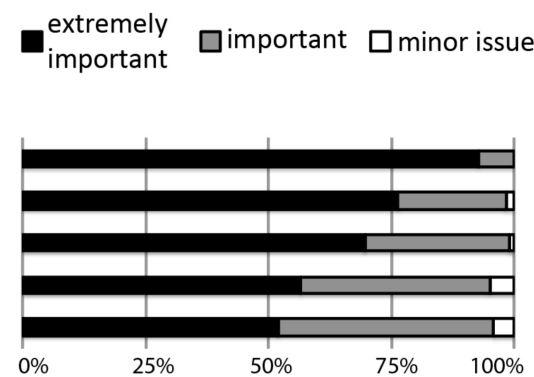

\section{2a: scientific integrity}

honest reporting of findings

conflict of interest

due credit to peers and associates

intellectual property rights

referencing

\section{2b: social responsibility}

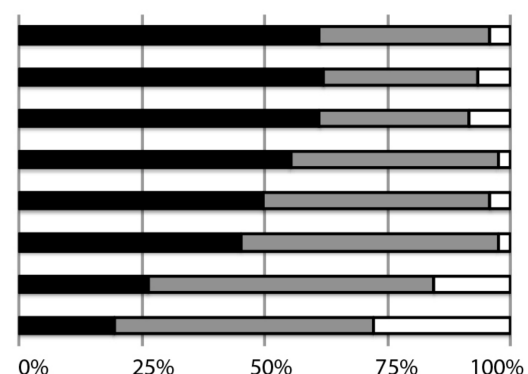

stewardship of the environment human rights

sustainability of natural resources

communication of Earth sciences to wider public

consultation with all stakeholders

respect

role of Earth scientists in relation to the media

geoheritage concerns

\section{2c: aboriginal concerns}

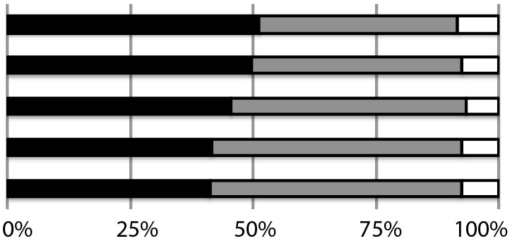

training and work opportunities

aboriginal thinking

land rights

role of community

inclusiveness

\section{2d: corporate ethics}

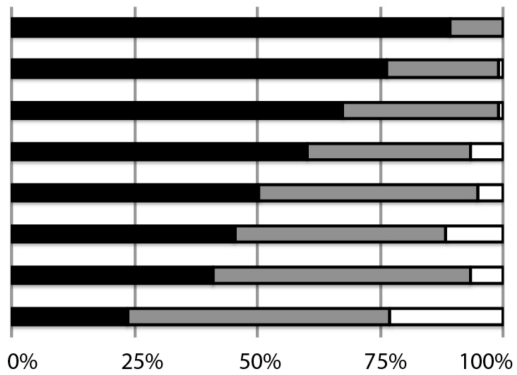

health and safety

conflict of interest

legal responsibility

confidentiality

fairness

whistleblowing

professional development

loyalty

\section{2e: fieldwork}

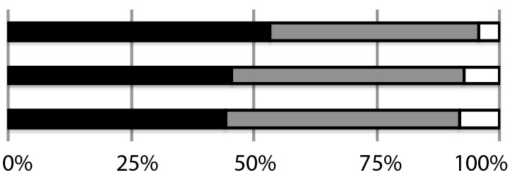

public and private property rights property owners "right to know", "right to withdraw access"

"leave no trace" philosophy

Figure 2. Survey results divided by category. Results within each category are sorted by decreasing importance, not in the order they were presented in the survey. 
Significant factors in the work of geoscientists are aspects of working with aboriginal communities. Whereas these considerations are not unique to geoscientists, they can play a more significant role in their work when compared to many other fields of science, and so we include them as significant considerations in relation to ethical issues in the work of geoscientists. Figure $2 \mathrm{c}$ highlights the responses to consideration of the relative importance of criteria with respect to aboriginal concerns. Training and work opportunities ranked highest in terms of extreme importance at just over $50 \%$, with aboriginal thinking at $49 \%$. In all, over $87 \%$ of respondents considered that all of the suggested criteria around aboriginal concerns to be important or extremely important.

Targeted aspects of corporate ethical considerations are summarised in Figure 2d. These data indicate that over $50 \%$ considered health and safety, legal responsibility, confidentiality, conflict of interest and fairness to be extremely important, whereas less than $25 \%$ considered loyalty important. Overall, over $77 \%$ of respondents considered all criteria suggested to be important or extremely important. In addition to those aspects included in our survey, one respondent suggested that we should also consider "failure to act ethically in hiring and employment decisions" as this is in fact a major breach of ethical behaviour, and one that this particular respondent had observed on numerous occasions.

Some geoscientists do not always give much consideration to where they are in relation to private or public lands. With this in mind, we included several criteria in the aspect of fieldwork. These results are summarized in Figure 2e. Property rights were considered extremely important in $53 \%$ of the responses, with over $91 \%$ of respondents considering all criteria as important to extremely important.

These data collectively indicate that the geoscience community considers key targeted aspects of potentially ethically charged issues within the realm of geoscience and beyond, to be of importance or extreme importance.

In addition to inviting respondents to consider what they thought to be important within the selected categories, we shared a list of potential areas in which ethical considerations might arise, and asked them to identify all from the list that they had personally observed in an Earth sciences context, while clarifying that the question was not asking them to reveal whether they were directly involved, simply whether they had ever encountered any of the considerations presented. In other words, this question moved beyond what individuals thought to be important to what they observed as violations of potentially important ethical considerations. We also invited participants to add other potential considerations to the list that we might have missed. The results are shown in Figure 3. This list includes criteria from all five of the categories we targeted, as outlined previously. We also included: negative comments about Canadian Earth science sector within Canada; and negative comments about Canadian Earth science sector abroad; but excluded them from Figure 3. As in Figure 2 we re-sorted the considerations according to how often they were selected. With the exception of observing human rights and legal violations (which were identified by $7 \%$ and $10 \%$ of respondents respectively), all other considerations were identified by more than $17 \%$ of respondents. Close to $80 \%$ of respondents noted that they had observed biased representation of information and lack of assigning credit to authors or originators of ideas.

In terms of prior formal education around ethical issues, Figure 4 reveals how respondents were introduced to ethical viewpoints and decision-making as it pertained to Earth sciences in particular. Over $60 \%$ indicated that their peers were a significant source, and $64 \%$ indicated that reading (websites, newspaper, society publication, or book) played an important role. Courses on ethical issues contributed to just $16 \%$ of respondents' early exposure to ethics; only $29 \%$ identified aspects of course work (including assignments, presentations, guest lectures, case studies) as contributing factors; and $16 \%$ identified workshops or sessions run at universities or by a society as important. Other avenues in which ethical considerations were accessed included discussions with a supervisor (37\%); ethics reading and examination for professional registration (41\%); and company or work-related sessions, workshops, or discussions (30\%). 


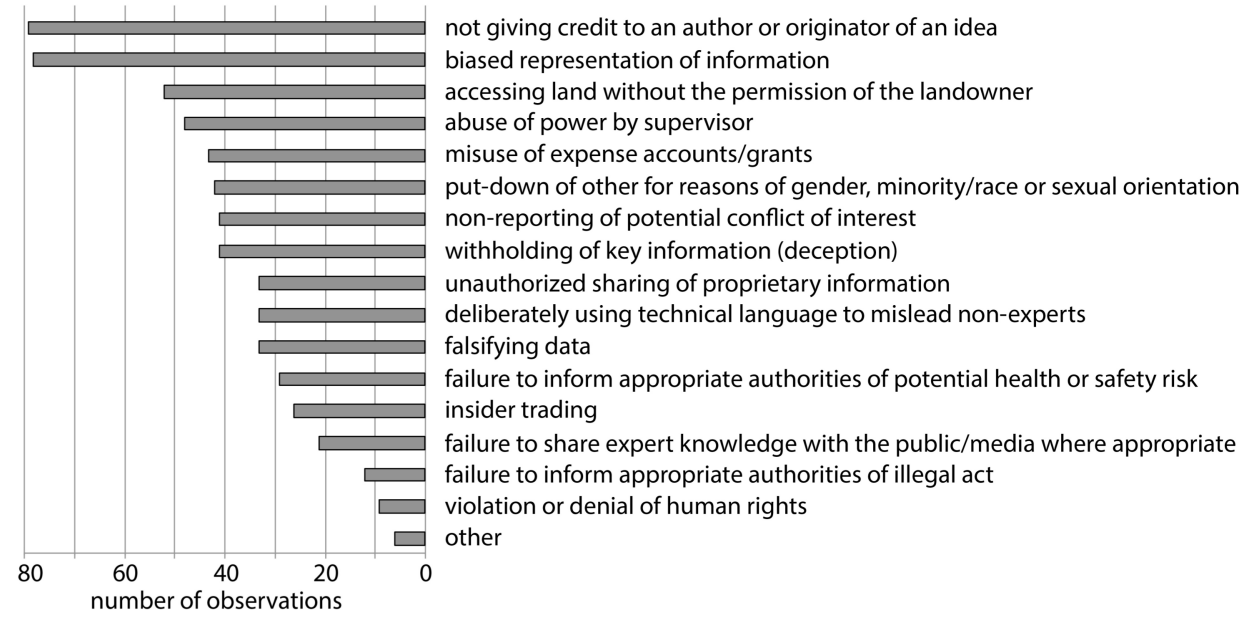

Figure 3. Ethical considerations observed by participants, and sorted from most frequent to least frequent responses.

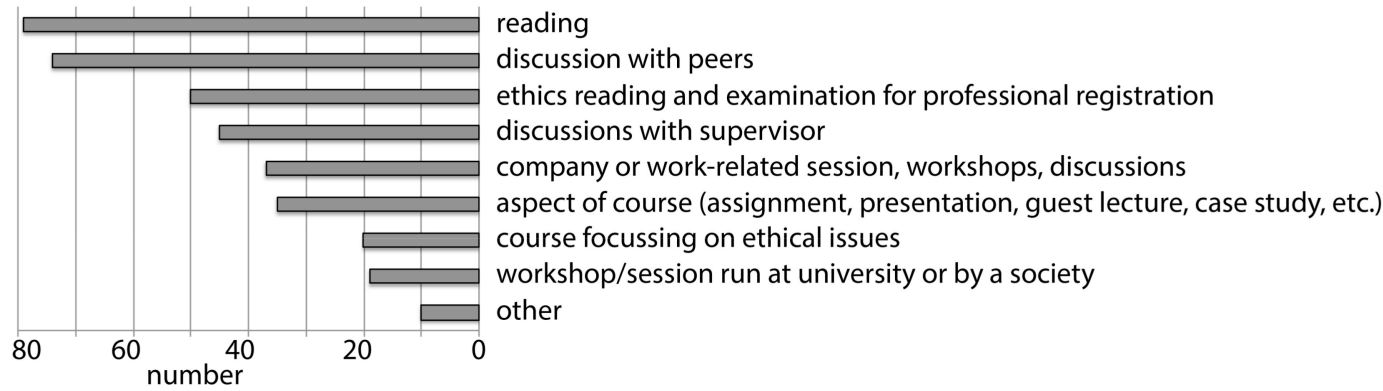

Figure 4. Introduction of respondents to ethical aspects, sorted by incidence.

Relatedly, when asked to consider whether Earth sciences undergraduate programs at their university prepared students for ethical decision making in their careers (Figure 5), 118 of the 123 participants responded, with only $31 \%$ of respondents agreeing or strongly agreeing that this was the case, and $17 \%$ strongly disagreeing with this statement. The remaining 52\% disagreed with the statement that their university had prepared them for ethical decision-making in their careers (Figure 5).

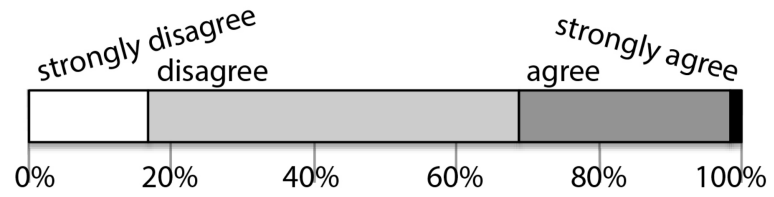

Figure 5. Responses to "My undergraduate program prepared me for ethical decision making in geoscience."

\section{Discussion}

The results show that there is indeed awareness and general agreement about the importance of geoethical considerations among the responding Canadian geoscientists. Respondents voluntarily completed the survey, and the low number of responses only allows us to make generalizations. None of the issues we presented in our survey were rejected by this group of respondents; on the contrary, almost all issues were considered important by the majority of respondents, and many issues were deemed extremely important. This we think is a strong indication that geoethics is a topic that warrants more discussion within the Canadian geoscience community. 
We find two issues with very strong support (i.e., overwhelming majority, over $80 \%$, says they are extremely important, and no respondent indicated these are minor issues) to be worth further consideration here: health and safety, and honest reporting. Of these, health and safety is covered by mandated rules and education at all workplaces in Canada and it seems that this approach has worked well in getting attention around this aspect. Interestingly, honest reporting can be considered to include two of the most-cited considerations observed, namely not giving credit and biased reporting (Figure 3), and clearly, this mismatch between recognition of its importance versus observed behaviours alone shows a need for more geoethical thinking.

Surprisingly, the broad categories ranked overall the least important (less than $55 \%$ of respondents marked them as extremely important) are about aboriginal issues and fieldwork. We are somewhat surprised by this, given that exploration and mining in Canada is tied to aboriginal land, or land claims, and much fieldwork is done on private land. However, we note that in another question, "accessing land" is listed as a consideration by 52 respondents, making it the third most-observed issue, i.e., many participants do see it as important (Figure 3). Issues within the other categories that have low agreement are geoheritage (several respondents note that they do not know the meaning of this term), loyalty, role of Earth scientists in relation to media, whistleblowing, professional development, and even respect.

As several respondents pointed out, some of the considerations we listed-e.g., falsifying data, deception, abuse of power, insider trading-are truly criminal activities. We were expecting that these would have been observed in isolated cases only and are therefore disturbed to see that about a quarter of our respondents have encountered these in their work. We do not think (or want to think) that these numbers would scale up to the total number of geoscientists. However, this finding should be seen as a call for action.

Our limited sample size prevents us from analysing the data in a more selective fashion, for example by comparing responses by sector (industry, government, academia). It is possible that the survey attracted individuals who are most astute to geoethics issues and thus more likely to place importance on the issues we raised. But we think that we are only seeing the proverbial tip of the iceberg in our responses, meaning that a larger sample size may shift the overall distribution away from extremely important without changing the overall answers. It is worrying to see even in our small and self-selected sample, so many instances of ethical considerations observed at work. Each geoscience sector has set its own ethical regulations, for example one required ethics examination in professional societies, or the peer-review system for vetting publications in academia and government. We wonder if these regulations are insufficient, and if additional mechanisms should be strengthened. Yet whistleblowing (without the danger of negative consequences) is not considered a priority item by our participants. Maybe professional societies should not only set an ethics exam and pursue blatant cases, but need also to play a bigger role in keeping their members informed about evolving ethical issues, in creating channels for reporting, and in supporting their members informally. Government and academic employees are not required to pass an ethics exam, and our survey is not large enough to ask which sector may experience more ethical issues. However, one may try a preventative mandated ethics training similar to workplace health and safety, where any such training is currently lacking.

Figure 4 shows that at present, informal activities—reading and discussions with peers-are the prevalent paths into geoethics, followed by requirements by the profession (ethics exam, company events). All formal educational activities (course, assignment, workshop) have the lowest ranking. Over two thirds of respondents state that their undergraduate education had not prepared them for ethical decision making (Figure 5). Both Figures 4 and 5 show that academia could play a larger role in drawing attention to geoethics. These data (Figures 4 and 5), are perhaps the most telling in terms of a call to action for educators, and indeed, for the broader geoscience community: lack of critical thought around potential ethical considerations cannot become an excuse for poor judgement. 
As educators our survey results confirm the suspicion we had at the outset that issues on geoethics need to be addressed, particularly as it is likely that some unethical behaviour is often a naïve response rather than a deliberate intentional poor choice. There was a time in the not too distant past when slavery was acceptable amongst "civilized" society: today we abhor it. Similarly with many geoethical issues: we blindly follow conventional ways of operating or viewing a situation, without thought as to whether there might be, or ought to be a better way. The last question of our survey welcomed ideas around ways to teach about ethics in the geosciences; respondents suggested case studies, role plays, discussions, workshops, and even courses in both undergraduate and graduate student education. All these are valuable options, and ones we are currently pursuing as we move forward from here. It should be noted that a small number of respondents believed that undergraduate programs were not the place to teach ethics.

\section{Recommendations and Conclusions}

Respondents have pointed out the importance of geoethics, and several deficiencies in our current approach. We make the following suggestions:

1. Academia needs to draw attention to geoethics, and make an honest effort at preparing students for ethical decision making.

2. Professional societies could provide a better service for members with respect to finding information on geoethics. For example, they may appoint an individual, an ombudsperson, who can be approached in confidence by members for consultation and to determine next steps where appropriate.

3. Data from this survey suggest we, the Canadian geoscience community, are presented here with a call to action, a process of critical thinking around our actions and indeed, our inactions, if we are to best serve the common good.

4. Interactions between Earth scientists and the media need to be improved. Geoscientists not only should feel confident adding their voices to current issues, and not withhold information that is crucial for decisions involving geoscience, they should be approachable by members of the media. Communicating our science with the public is an aspect of our science that is increasingly important, and one that should also be included in our undergraduate programs.

5. Ties with aboriginal communities need to be strengthened. Canada's economy has a significant proportion of resources, a lot of resource extraction or movement happens on or in the vicinity of aboriginal land, and if done right, aboriginal communities can prosper in partnerships with industry.

Our findings suggest that the Canadian geoscience community and the public must be made aware of (geo)ethical issues and to begin discussions around such issues. In particular, we call on the various sectors-professional organizations, government, and academia-to revisit their geoethics expectations, discuss them, and educate the community. The data presented here indicate that geoethics is no longer a topic that we can consider adequately dealt with by only an ethics exam, but that we as educators are called to create curricular material, including case studies and discussion ideas, to train students in effective decision-making techniques.

Our findings are based on a limited sample number and we should be careful projecting our results to the Canadian or even the international geoscience community as a whole. For a confirmation, a much larger and more representative survey would be required. However, at this point we cannot deny the results from our survey of a small group of geoscientists. At the very least, these respondents perceive the need for better ethical training and suggest that geoscientists have to face and act on the new discipline of geoethics.

Acknowledgments: We thank all participants for their time and input, and professional societies for forwarding a call to participate to their members. Undergraduate student Intesar Raisuddin helped with data analysis. Our study was vetted and approved by Research Ethics Boards at the University of Toronto (protocol reference 
number 28630) and Dalhousie University (protocol number 2013-2928). We gratefully acknowledge the suggestions of three reviewers in bringing this manuscript to its final form.

Author Contributions: A.M.R. and C.-G.B. conceived and designed the survey; A.M.R. set up the survey; both authors analyzed the data; C.-G.B. created figures; A.M.R. wrote the initial draft of the paper.

Conflicts of Interest: The authors declare no conflict of interest.

\section{References}

1. Geoscientists Canada. Available online: https://geoscientistscanada.ca (accessed on 30 September 2017).

2. AGID International Working Group of Geoethics. Available online: http://tierra.rediris.es/Geoethics_ Planetary_Protection/AGID_Geoethics_International_Declaration.htm (accessed on 30 September 2017).

3. Varet, J. Global Approach to geoethics: A first attempt. In Proceedings of the Mining Pribram Symposium, International Session on Geoethics, Pribram, Czech Republic, 15-19 October 2007.

4. Di Capua, G.; Peppoloni, S.; Bobrowsky, P. Cape Town Statement on Geoethics. Available online: http: / / www.geoethics.org/ctsg (accessed on 31 October 2017).

5. Matteucci, R.; Gosso, G.; Peppoloni, S.; Piacente, S.; Wasowski, J. A hippocratic oath for geologists. Ann. Geophys. 2012, 55, 365-369. [CrossRef]

6. Matteucci, R.; Gosso, G.; Peppoloni, S.; Piacente, S.; Wasowski, J. The "geoethical promise": A proposal. Episodes 2014, 37, 190-191.

7. Peppoloni, S.; Di Capua, G. Geoethics and geological culture: Awareness, responsibility, and challenges. Ann. Geophys. 2012, 55, 335-341. [CrossRef]

8. Peppoloni, S.; Di Capua, G. The meaning of geoethics. In Geoethics: Ethical Challenges and Case Studies in Earth Sciences; Wyss, M., Peppoloni, S., Eds.; Elsevier: Amsterdam, The Netherlands, 2015; pp. 3-14. ISBN 978-0-12-799935-7.

9. IAGETH. Available online: http:/ / www.icog.es/iageth/ (accessed on 30 September 2017).

10. Mogk, D.; Bruckner, M. Teaching Geoethics across the Geoscience Curriculum. Available online: http: / / serc.carleton.edu/geoethics/index.html (accessed on 18 November 2017).

11. Dougherty, E.Y. Professional ethics of geologists: Discussion. Econ. Geol. 1958, 53, 496-497. [CrossRef]

12. Bok, D. Can ethics be taught? Chang. Mag. High. Learn. 1976, 8, 26-30. [CrossRef]

(C) 2017 by the authors. Licensee MDPI, Basel, Switzerland. This article is an open access article distributed under the terms and conditions of the Creative Commons Attribution (CC BY) license (http:/ / creativecommons.org/licenses/by/4.0/). 